\title{
JUURNAL.RU
}

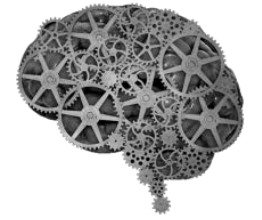

COMPANY GROUP "INTELLEKT"

\author{
Ефремов А.А., Писарева А.В., Николаев А.П. \\ Московский государственный технический университет им. Н. Э. Баумана \\ Москва, Россия
}

doi: 10.18411/lj2016-6-2-06

\section{Применение импедансного электрохирургического аппарата в онкохирургии и разработка модуля обратной связи}

Ключевые слова: импеданс, электрохирургия, онкохирургия, резка, коагуляция.

Цель работы: разработка принципа построения, создание и применение импедансных электрохирургических аппаратов (ИЭХА) в онкологии, обеспечивающих «щадящее» хирургическое вмешательство, при котором минимальны кровопотери, минимальны разрушения клеточных массивов оперируемых здоровых биотканей, существенно сокращается время заживления операционных ран.

Задачи: исследовать применение импедансных электрохирургических аппаратов в онкохирургии. Разработать принцип построения импедансного электрохирургического аппарата.

Mатериаль $u$ методы: в работе использованы проведенные ранее научные исследования в области электрохирургии, теории электрических цепей.

Pезультаты: проведен анализ использования электрохирургических аппаратов в лечении онкологических заболеваний, разработана структура импедансных электрохирургических аппаратов различного применения.

Заключение: предложен принцип построения импедансного электрохирургического аппарата, основанный на использовании автоматической обратной связи «электрический импеданс биоткани - электрохирургическое 
воздействие».

Высокочастотная электрохирургия (ЭХВЧ) - это метод хирургического воздействия на биологическую ткань посредством прохождения через нее высокочастотного электрического тока с целью резания или коагуляции. Рассечение тканей с помощью «электроножа» успешно выполнил в 1910 г. Черни. В России электрохирургический метод для лечения опухолей начал использовать В. Н. Шамов в клинике С. П. Федорова в 1910-1911 гг.

В электрохирургии используется переменный ток. Частота тока выбирается в диапазоне от 200 - 300 кГц до 3 - 4 мГц. Нижняя граница диапазона обусловлена тем, что на частотах ниже 200 - 300 кГц начинает проявляться нервно-мышечная стимуляция, возможно влияние на сердечнососудистую деятельность. Поэтому минимальная рабочая частота обычно превышает 200 кГц, ниже которой начинает проявляться вызывающее нежелательное сокращение мышц и болевые ощущения.

Тканевые эффекты электрохирургии основаны на преобразовании электрической энергии в тепловую:

1. Повышение температуры до $45^{\circ} \mathrm{C}$ не оказывает повреждающего действия на хорошо кровоснабжаемые ткани;

2. При температуре $46-70^{\circ} \mathrm{C}$ степень повреждения прямо пропорционально зависит от времени воздействия;

3. При $71-100^{\circ} \mathrm{C}$ происходит денатурация коллагена и гибель клеток;

4. При превышении температуры воздействия до $100^{\circ} \mathrm{C}$ внутриклеточная жидкость начинает испаряться, разрывая межклеточные соединения;

5. При воздействии выше $200^{\circ} \mathrm{C}$ вещество клетки распадается до неорганических соединений.

Применение электрохирургии в онкологии в качестве самостоятельного метода лечения получило большое распространение.

Электрокоагуляция оказывается весьма полезной при необходимости 
разрушения некоторых опухолей с нечеткими границами, например рака языка, новообразований слизистых оболочек рта, глотки, верхних дыхательных путей, прямой кишки, влагалища, мочевого пузыря, а также при ряде опухолей кожных покровов.

Очевидными достоинствами электрохирургии по сравнению с ножевыми вмешательствами являются:

1. Почти полная бескровность операции благодаря свариванию концов пересекаемых сосудов мелкого и среднего калибра;

2. Уменьшение опасности прививки раковых клеток в рану и опасности распространения инфекции благодаря свариванию и закрытию просветов лимфатических сосудов и щелей;

3. Снижение болей в ране благодаря коагуляции концов пересекаемых нервов.

Основные преимущества электрохирургии в онкологии выражаются в антибластичности и абластичности вмешательства. Электрокоагуляция ведет не только к прямому уничтожению опухолевых тканей, т.е. к онтибластическому воздействию, но и предупреждает распространение опухолевых клеток по ране и в глубину благодаря гибели этих клеток при соприкосновении с электронаконечником и закрытию просветов лимфатических и кровеносных сосудов в результате сваривания тканей.

Усиленная экссудация лимфы наружу предотвращает всасывание из раны и вовлечение опухолевых клеток в лимфатическое русло, т.е. снижает опасность развития метастазов.

Всё это способствует большей активности больных и помогает более быстрому восстановлению сил после операции.

Обнаженную опухоль этапно коагулируют биактивно-биполярным способом и вычерпывают коагулированные части электропетлей. Почти полная бескровность вмешательства позволяет выполнять операцию под контролем зрения. Предложена также коагуляция сосудистого сплетения желудочков мозга 
для уменьшения секреции спинномозговой жидкости при водянке мозга.

Электрохирургические методы лечения являются методом выбора при лечении папиллом мочевого пузыря и начальных форм рака (эндо- и трансвезикальные электрокоагуляции и электрорезекции пузыря). Электрокоагуляция и электроконизация шейки матки при упорных ее эрозиях являются также методом выбора и хорошим профилактическим средством для устранения предраковых ее заболеваний.

Для измерения импеданса схемой формирования диагностического импульса, управляемой соответствующей схемой управления, связанной с микропроцессорным блоком управления, формируется диагностический импульс тока, который подается на электрохирургические электроды в моменты отсутствия ВЧ напряжения. При этом измеряется напряжение на электродах и рассчитывается величина электрического импеданса.

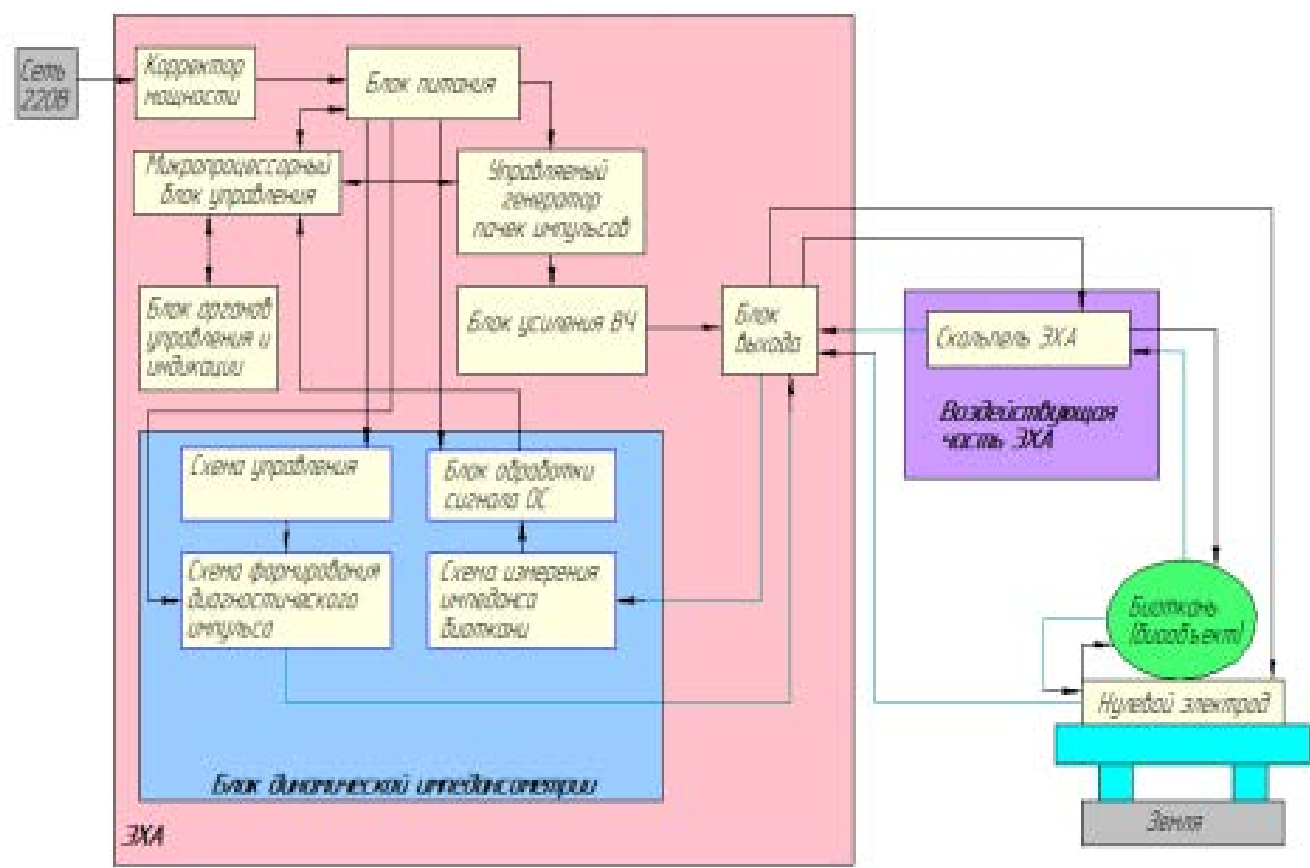

Рис. 1. Структурная схема электрохирургического аппарата с блоком динамической импедансометрии.

Информация об измеренном импедансе поступает на блок обработки сигнала обратной связи, где в зависимости от величины преобразуется в 
двоичный цифровой код, который поступает на вход микропроцессорного блока управления.

Связь блока управления модуля динамической импедансометрии с микропроцессорным блоком управления необходима для изменения параметров диагностического импульса с учётом текущего режима работы ЭХВЧ аппарата.

Система измерения импеданса биоткани предполагает регистрацию тока и напряжения в цепи активного электрода, а также посредством деления в вычислителе по формуле:

$$
\mathrm{R}=\frac{U}{I}
$$

Это дает возможность определения искомого импеданса.

Данные измерения напряжения и тока проводятся на частоте электрохирургического воздействия, равной 4400 мГц. Сами измерения проводятся выборочно с частотой 2200 мГц. Система измерения импеданса биоткани изображена на рис. 2.

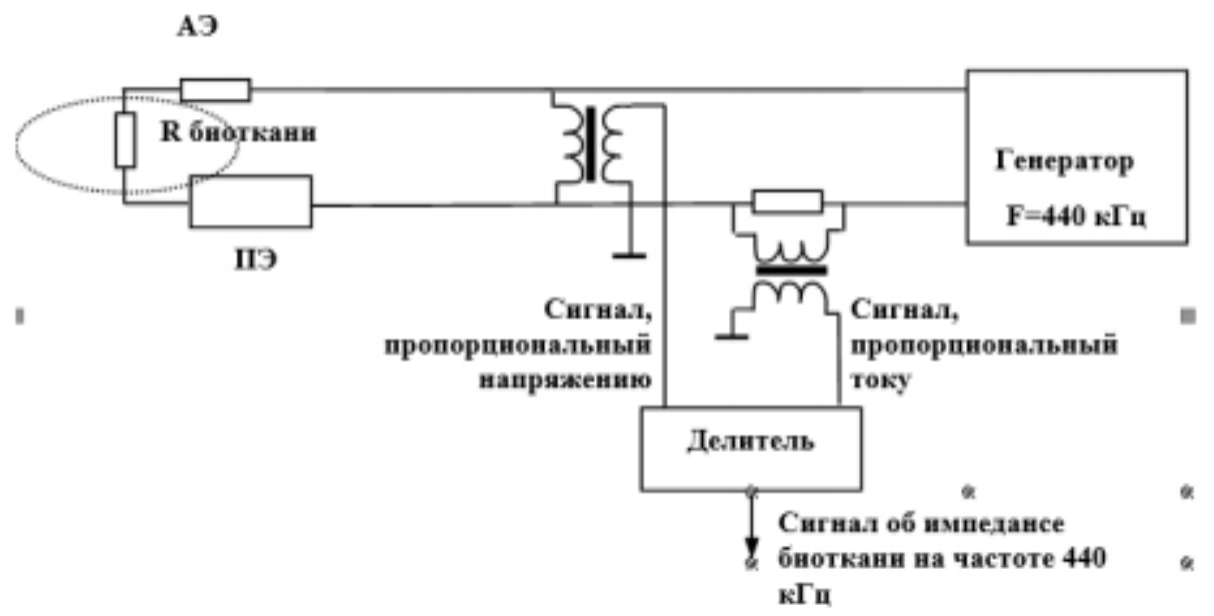

Рис. 2. Система регистрации импеданса биоткани на поверхности

Таким образом, импедансные электрохирургические аппараты находят широкое применение в области онкохирургии, а блок обратной связи позволяет свести на ноль риск возникновения ожог в месте оперативного вмешательства, что является самым распространенным вариантом осложнения при электрохирургических процедурах. 


\section{Литература:}

1. Белик Д.В. Импедансные электрохирургические аппараты / Автореферат диссертации на соискание ученой степени доктора технических наук. 2003. -C. 23-27.

2. Сердюченко Д.А., Заходяйченко М.А., Обоснование необходимости введения блока обратной связи в электрохирургический аппарат. -2016. C. 7-9.

3. Аронов А.М., Белик Д.В. Некоторые направления реализации и совершенствования аппаратов для электрохирургии / Сибирский медицинский журнал. - 2000. -№3. -С. 37-39. 